\title{
Full inactivation of alphaviruses in single particle and crystallized forms
}

\author{
Robert M. Lawrence ${ }^{1,2,3}$, James D. Zook ${ }^{3,4}$, Brenda G. Hogue $e^{1,2,3,5^{*}}$ \\ ${ }^{1}$ Biodesign Institute, ${ }^{2}$ Biodesign Center for Infectious Diseases and Vaccinology, ${ }^{3}$ Biodesign Center for \\ Applied Structural Discovery, ${ }^{4}$ School of Molecular Sciences, ${ }^{5}$ School of Life Sciences, Arizona State \\ University, Tempe, AZ 85287, USA
}

*Corresponding author.

E-mail address: Brenda.Hogue@asu.edu

\begin{abstract}
Inherent in the study of viruses is the risk of pathogenic exposure, which necessitates appropriate levels of biosafety containment. Unfortunately, this also limits the availability of useful research instruments that are located at facilities not equipped to handle infectious pathogens. Abrogation of viral infectivity can be accomplished without severely disrupting the physical structure of the virus particle. Virus samples that are verifiably intact but not infectious may be enabled for study at research facilities where they would otherwise not be allowed. Inactivated viruses are also used in the development of vaccines, where immunogenicity is sought in the absence of active infection. We demonstrate the inactivation of Sindbis alphavirus particles in solution, as well as in crystallized form. Inactivation was accomplished by two different approaches: crosslinking of proteins by glutaraldehyde treatment, and crosslinking of nucleic acids by UV irradiation. Biophysical characterization methods, including dynamic light scattering and transmission electron microscopy, were used to demonstrate that the glutaraldehyde and UV inactivated Sindbis virus particles remain intact structurally. SDS-PAGE was also used to show evidence of the protein crosslinking that was expected with glutaraldehyde treatment, but also observed with UV irradiation.
\end{abstract}

Keywords:

Virus inactivation; glutaraldehyde; UV irradiation; Sindbis; crystallization; single particle 


\section{Introduction}

It is possible to modify the chemistry of a virus in a manner that abolishes infectivity but does not significantly alter the physical structure. Such modification enables biophysical studies to be carried out on viruses without the pathogenic risks that would otherwise prevent the use of instrumentation and techniques that are not compatible with the appropriate biosafety regulations. We report here two different approaches to thus inactivate the Sindbis virus, both in single particle and crystallized form.

Sindbis virus (SINV) is one of 32 viruses currently classified in the family Togaviridae, which also includes Chikungunya virus (CHIKV), Semliki Forest virus (SFV), Ross River virus (RRV), and Rubella virus (RUBV) (Adams et al., 2015, 2014). SINV, CHIKV, SFV and RRV are arboviruses that are carried by mosquitoes and transmitted to humans or other vertebrates. Togaviridae are evolutionarily linked to Flaviviridae (Strauss and Strauss, 2001), which includes other structurally similar arboviruses such as Yellow Fever virus (YFV), West Nile virus (WNV), dengue virus (DENV), and Zika virus (ZIKV). Sindbis virus is characterized by a host-derived lipid membrane envelope, a positive-strand RNA genome, and three structural proteins (C, E1, E2) of which there are 240 copies each. The RNA genome is enclosed within an assembly of the capsid $(C)$ proteins. This capsid is surrounded by the lipid envelope which anchors the E1 and E2 envelope proteins. E1 and E2 associate to form heterodimers, which further assemble into 80 trimeric 'spikes' that protrude to the exterior from the lipid envelope. The capsid proteins and the envelope proteins are both arranged icosahedrally with a $\mathrm{T}=4$ symmetry (Paredes et al., 2005, 1993). Small angle neutron scattering measurements determined the precise diameter of Sindbis virus as 67.6 $\pm 2.5 \mathrm{~nm}$ at pH 7.2, and $72.0 \pm 2.8 \mathrm{~nm}$ at pH 6.4 (He et al., 2012). The Sindbis virus is known to cause rashes, fever, joint and muscle pain, and symptoms can be chronic in some cases (Adouchief et al., 2016). It can be routinely propagated to very high densities under biosafety level 2 conditions (Hernandez and Brown, 2005), and it is used as a prototypical model of study for the alphavirus genus of Togaviridae (Adams et al., 2014).

A variety of direct treatment methods have been described that will effectively abolish the infectivity of a virus for the purposes of sanitation, but not always with an interest in preserving the physical structure (Mcdonnell and Russell, 1999). Inactivation methods that are not reliant on genetic manipulation or irreversible physical denaturation include chemical crosslinking (aldehydes, $\beta$ propiolactone), radiation exposure (UV, gamma), and alkylation of nucleic acids ( $\beta$-propiolactone, binary ethylene imine). These methods have been used to partially or fully inactivate a variety of enveloped and non-enveloped viruses (Delrue et al., 2012).

Of the aldehydes, glutaraldehyde $\left(\mathrm{C}_{5} \mathrm{H}_{8} \mathrm{O}_{2}\right)$ is perhaps the most reactive and efficient at producing stable protein crosslinks (Bowes and Cater, 1968; Nimni et al., 1987). The various mechanisms by which glutaraldehyde crosslinking may occur are dependent on the multiple molecular conformations enabled by its five carbon dialdehyde nature (Migneault et al., 2004). Although the mechanisms are not entirely predictable and have not been fully described, the reaction usually begins with nucleophilic addition from the $\varepsilon$-amine group of lysines, and can proceed to crosslink within a protein chain or between separate, but adjacent protein chains. Glutaraldehyde crosslinking is only slightly reversible at physiological pH (pH 7- pH 9) (Okuda et al., 1991). Other nucleophilic functional groups in proteins have also been shown to be reactive with glutaraldehyde, including thiol (cysteine), phenol (tyrosine), imidazole (histidine), and the free $\alpha$-amino group on the $\mathrm{N}$-terminal residue (Avrameas and Ternynck, 1969; Habeeb and Hiramoto, 1968). Formaldehyde has also been shown to be reactive with these functional groups in forming crosslinks, in addition to amide (asparagine, glutamine), guanidyl (arginine), and indole (tryptophan) groups (Fraenkel-Conrat and Mecham, 1949; Fraenkel-Conrat and Olcott, 1948; 
French and Edsall, 1945). Formaldehyde is known to also react with nucleic acids to form crosslinks (Huang and Hopkins, 1993; Lu et al., 2010), but this activity is restricted with glutaraldehyde (Hopwood, 1975; Sewell et al., 1984).

UV radiation is also capable of inactivation by various mechanisms (Ravanat et al., 2001). Nucleic acids absorb within the UVC (100-280 nm) and UVB (280-320 nm) range, with maximal absorbance near 260 $\mathrm{nm}$. Direct UVC and UVB exposure induces nucleic acid crosslinking between adjacent pyrimidines, forming either cis-syn cyclobutane pyrimidine dimers (CPDs) or pyrimidine [6-4] pyrimidone photoproducts ([6-4]PPs) as the major crosslinks. Both photoproducts are produced efficiently in DNA under UVC conditions ( $254 \mathrm{~nm}$ ), and it appears that CPDs become relatively more prevalent as the wavelength increases into the UVB range (Ravanat et al., 2001; Yoon et al., 2000). UV radiation also catalyzes the formation of reactive oxygen species (from either endogenous or exogenous sensitizer molecules) that go on to indirectly cleave or otherwise damage nucleic acids (Ravanat et al., 2001) as well as proteins (Eischeid and Linden, 2011; Wigginton et al., 2012, 2010). Crosslinking reactions are also known to take place between proteins and nucleic acids, primarily involving thymine reacting with lysine (Saito and Matsuura, 1985; Shetlar et al., 1975), arginine, and cysteine (Schott and Shetlar, 1974). Protein to protein crosslinking has not been extensively studied, but has been observed as well (Prinsze et al., 1990). Although most investigation into the effect of UV on nucleic acids is targeted on DNA, the principles can generally be extended to RNA as well.

Although decades of research have been invested into describing the various effects of aldehydes or UV irradiation on nucleic acids and proteins in isolation, the understanding of these processes in the macromolecular context of a virus is still quite limited (Wigginton et al., 2012). The proximity of a condensed viral genome to capsid proteins, and the tight multimeric packing of these proteins produces a high potential for a variety of cross reactions to occur under the appropriate conditions.

\section{Experimental Methods}

\subsection{Preparation and Purification of Sindbis Virus}

Methods for the cultivation, purification, and quantification of Sindbis virus were adapted from the established protocols by Hernandez, et al., (Hernandez, 2005). Baby hamster kidney (BHK) cells were cultivated by passaging in minimal essential medium (MEM) with supplements ( $5 \%$ fetal bovine serum, $5 \%$ tryptose phosphate broth, $2 \mathrm{mM} \mathrm{L-glutamine,} 50 \mu \mathrm{g} / \mathrm{mL}$ gentamicin). Cells were grown in $875 \mathrm{~cm}^{2}$ multi-level flasks until nearly confluent in preparation for large-scale infections. A multiplicity of infection (MOI) of 0.1 was used to inoculate, and the cells were maintained during the infection period in Glasgow minimal essential medium (GMEM) containing $2 \mathrm{~g} / \mathrm{L} \mathrm{NaHCO}_{3}$ in addition to the other supplements used with MEM. Following a $24 \mathrm{~h}$ infection period, growth medium was clarified by centrifugation at $1000 \mathrm{xg}$ for $10 \mathrm{~min}$ to remove cell debris.

The harvested virus was purified using isopycnic sedimentation. Continuous gradients of potassium tartrate (dibasic) in PN buffer (50 mM PIPES pH 7.2, $100 \mathrm{mM} \mathrm{NaCl}$ ) were prepared in $19 \mathrm{~mL}$ volumes with a $15-37 \%$ concentration range. Gradients were overlayed with $20 \mathrm{~mL}$ of the clarified supernatant. Sindbis virus was sedimented in the continuous gradient by ultracentrifugation in rotor SW $32 \mathrm{Ti}$ (Beckman Coulter) at $100,000 \times \mathrm{g}$ for $4 \mathrm{~h}$ at $4{ }^{\circ} \mathrm{C}$, and virus bands were extracted by bottom puncture of the $40 \mathrm{~mL}$ ultracentrifuge tubes. Extracted virus bands were pooled, dialyzed in PN buffer to remove potassium tartrate, and applied to a second round of continuous gradient purification to concentrate the virus band into a smaller volume. Dialysis in PN buffer was repeated to remove potassium tartrate. 
An additional sedimentation step was applied for preparation of the sample used in crystallization. Following dialysis, the purified virus in PN buffer was centrifuged for $2 \mathrm{~h}$ at 100,000 x g in rotor SW $55 \mathrm{Ti}$ (Beckman Coulter) to pellet the virus, which was resuspended in PN buffer to a concentration of 1 $\mathrm{mg} / \mathrm{mL}\left(\sim 3 \times 10^{11} \mathrm{pfu} / \mathrm{mL}\right)$. Concentration was determined by a modification of the Lowry Assay method (Markwell et al., 1978).

\subsection{Crystallization}

Methods for producing microcrystals of Sindbis have been previously reported (Lawrence et al., 2015), and are based on previously established methods for macrocrystal production (Harrison et al., 1992). Briefly, crystallization was induced by vapor diffusion using the hanging drop method. Hanging drops consisted of equal parts of $1 \mathrm{mg} / \mathrm{mL}$ Sindbis virus in PN buffer and the precipitant solution in a $10 \mu \mathrm{L}$ volume. The precipitant was $5.5 \% \mathrm{w} / \mathrm{v}$ PEG $8000,7.5 \% \mathrm{w} / \mathrm{v}$ glycerol, and $0.24 \mathrm{M} \mathrm{KCl}$, and it was added to each reservoir in a $0.5 \mathrm{~mL}$ volume. Crystals began to appear in hanging drops after 5-6 days of equilibration at $4{ }^{\circ} \mathrm{C}$. Microcrystals with a diameter of $10-20 \mu \mathrm{m}$ were produced at a density of approximately $10^{6}$ crystals $/ \mathrm{mL}$.

\subsection{UV Irradiation}

Samples of purified Sindbis virus were exposed to increasing doses of UVC radiation to determine the minimum amount required for full inactivation. A Stratalinker UV Crosslinker Model 1800 was used to generate $254 \mathrm{~nm}$ UVC radiation at a rate of $60 \mu \mathrm{joules} / \mathrm{cm}^{2} / \mathrm{s}$.

Single particle samples of Sindbis virus suspended in PN Buffer at a concentration of $0.07 \mathrm{mg} / \mathrm{mL}$ ( $2 \mathrm{x}$ $10^{10} \mathrm{pfu} / \mathrm{mL}$ ) were subjected to $1500,3000,4500,6000,9000,12000$, and $15000 \mu \mathrm{joules} / \mathrm{cm}^{2}$ of UVC radiation. Samples were irradiated in $1 \mathrm{~mL}$ volumes deposited in $9.4 \mathrm{~cm}^{2}$ wells in 6 -well plates. The samples were placed at a distance of $18 \mathrm{~cm}$ from the radiation source.

Sindbis microcrystals were similarly irradiated with UVC by inverting the hanging drops while still attached to the cover slide and exposing the microcrystals to $40,000 \mu$ joules $/ \mathrm{cm}^{2}$ of UVC radiation. 20 crystal drops ( $100 \mu \mathrm{L}$ ) were exposed, pooled, and diluted to a volume of $1 \mathrm{~mL}$ in PN buffer, which was dialyzed in PN buffer to remove precipitant compounds and further dissolve crystals to the extent possible. This is the neat concentration $\left(10^{\circ}\right)$ of sample used in the infectivity assays and SDS PAGE analysis.

\subsection{Glutaraldehyde Treatment}

Glutaraldehyde was added directly to small volumes of purified Sindbis virus particles in PN Buffer. To determine the minimum amount required for full inactivation, volumes of $1 \mathrm{~mL}$ were prepared with Sindbis virus at concentrations of $0.07 \mathrm{mg} / \mathrm{mL}\left(\sim 2 \times 10^{10} \mathrm{pfu} / \mathrm{mL}\right)$ and glutaraldehyde concentrations of $0.0001 \%, 0.001 \%, 0.01 \%$, and $0.1 \% \mathrm{v} / \mathrm{v}$, incubated for $24 \mathrm{~h}$ at $4{ }^{\circ} \mathrm{C}$, then dialyzed in PN buffer to remove glutaraldehyde.

Treatment of Sindbis virus microcrystals with glutaraldehyde was carried out by vapor diffusion in a manner similar to methods developed for protein crystals (Lusty, 1999). After microcrystals had formed in vapor diffusion drops, glutaraldehyde was added directly to the reservoir volume to a concentration $0.1 \% \mathrm{v} / \mathrm{v}$. Crystal trays were allowed to continue incubating at $4{ }^{\circ} \mathrm{C}$ for 6 days to allow glutaraldehyde to reach equilibrium with the vapor diffusion drop. The volume of 20 crystal drops ( $100 \mu \mathrm{L})$ was pooled and diluted to a volume of $1 \mathrm{~mL}$ in PN buffer, which was dialyzed in PN buffer to remove glutaraldehyde and precipitant compounds, and dissolve crystals to the extent possible. This volume is the neat concentration $\left(10^{\circ}\right)$ of sample used in the infectivity assays and SDS-PAGE analysis. 


\subsection{Infectivity Assays}

Infectivity of inactivated viruses was quantified by plaque assay titration, and confirmed qualitatively by propagation of inoculated cells. For plaque assays, ten-fold serial dilutions of inactivated samples were prepared in $500 \mu \mathrm{L}$ volumes ranging from $10^{\circ}$ (neat concentration) to $10^{-8}$. The diluent was PN buffer supplemented with $3 \% \mathrm{v} / \mathrm{v}$ FBS. 6-well plates of BHK cell monolayers grown to near confluence that had been seeded 1 day prior were used for the plaque assay. Each well was inoculated with $200 \mu \mathrm{L}$ of a given dilution for $60 \mathrm{~min}$ and overlayed with $2 \mathrm{~mL}$ of $1 \%$ agarose (type I) in MEM. All dilutions $\left(10^{0}-10^{-8}\right)$ were titered in duplicate. Plates were incubated for 2 days at $37{ }^{\circ} \mathrm{C}$ in the presence of $5 \% \mathrm{CO}_{2}$. Wells were stained by adding $200 \mu \mathrm{L} /$ well of MTT blue (Thiazolyl blue tetrazolium bromide) at $5 \mathrm{mg} / \mathrm{mL}$ in phosphate buffered saline solution, and continued incubation for 2-3 hours to produce visibly contrasted plaques. The limit of detection for $200 \mathrm{uL}$ sample volumes assayed in duplicate wells is 2.5 $\mathrm{pfu} / \mathrm{mL}$.

For the inoculation assays, $25 \mathrm{~cm}^{2}$ flasks with near confluent growth were each inoculated with $200 \mu \mathrm{L}$ of inactivated Sindbis at neat concentration from all inactivation treatments. Each flask was supplemented with $3 \%$ FBS. Following a 60 min inoculation period, cells were returned to GMEM with supplements ( $5 \%$ fetal bovine serum, $5 \%$ tryptose phosphate broth, $2 \mathrm{mM} \mathrm{L}$-glutamine, $50 \mathrm{\mu g} / \mathrm{mL}$ gentamicin, $2 \mathrm{~g} / \mathrm{L} \mathrm{NaHCO}_{3}$ ), and growth continued overnight. Cells were passaged daily in an upward manner to $75 \mathrm{~cm}^{2}, 150 \mathrm{~cm}^{2}$, and then $300 \mathrm{~cm}^{2}$ for a total of 3 passages. Media was discarded and replenished at each passage. Full inactivation was indicated by continued growth and lack of cytopathic effects throughout the series of passages. Alternatively, infectivity was indicated by retarded growth and the eventual spread of cytopathic effect throughout the flask at which point passages were discontinued. The cytopathic effect was indicated by the thinning of cell volume and eventual detachment of cells from the flask surface.

\subsection{Denaturing polyacrylamide gel electrophoresis (SDS-PAGE)}

$10 \%$ polyacrylamide gels were prepared and run according to protocols reported by Schägger (Schägger, 2006). Samples were mixed with a reducing $4 \mathrm{X}$ sample buffer ( $27 \% \mathrm{w} / \mathrm{v}$ SDS, $133 \mathrm{mM} \mathrm{Tris-HCl} \mathrm{pH} \mathrm{8.0,}$ $2.5 \mathrm{M} \beta$-mercaptoethanol, $27 \% \mathrm{v} / \mathrm{v}$ glycerol, $133 \mu \mathrm{M}$ bromophenol blue) and heated at $95^{\circ} \mathrm{C}$ for 10 minutes prior to loading. Gels were silver stained using a commercial kit (Pierce).

\subsection{Dynamic Light Scattering (DLS)}

The hydrodynamic radius and polydispersity index (PDI) of Sindbis virus particles in solution was estimated by Dynamic light scattering (DLS) using a Spectro Size 302 instrument (Molecular Dimensions) with a $785 \mathrm{~nm}$ laser. A $10 \mu \mathrm{L}$ volume of each inactivated single particle sample was deposited to the underside of a siliconized glass cover slide. The DLS laser was directed toward the center of the droplet, and each measurement was compiled from a series of $10 \times 20$-second data recordings. Instrument settings included a shape factor of 1.0 , exponent of 3.0 , count rate of 100 , viscosity of $1.013 \mathrm{cP}$, scattering angle of $150^{\circ}$, and refractive index of 1.339 . The presence of a sigmoidal autocorrelation function on a semi-log $x$-axis in the output data was indicative of a signal that could be reliably correlated to the sample. The CONTIN analysis method (Provencher, 1982) was used to generate a hydrodynamic radius value from the data, and a cumulants analysis method (Frisken, 2001) was used to produce a PDI value for the observed monodispersed peak. The hydrodynamic radius value includes radius contributions from the hydration shell surrounding the particle. Low PDI values correspond to highly monodispersed samples, and values greater than 0.7 are generally considered to have a size distribution that is too broad for DLS (International Standard ISO13321, 1996; International Standard ISO22412, 2008). 


\subsection{Transmission Electron Microscopy (TEM)}

A Philips CM 12 transmission electron microscope was operated at $80 \mathrm{kV}$ to generate bright field images of negatively stained virus particles. Formvar coated 400-mesh copper grids (Electron Microscopy Sciences) were used for single particle samples in solution. A $5 \mu \mathrm{L}$ volume of sample was deposited onto a grid and incubated for 5 min. Grids were negatively stained with a $5 \mu \mathrm{L}$ volume of $1 \%$ uranyl acetate for $30 \mathrm{sec}$ and afterwards rinsed briefly with a $5 \mu \mathrm{L}$ volume of PN buffer. Residual volume was removed from the grid surface by absorptive wicking following each step.

\section{Results}

\subsection{Inactivation by UVC Irradiation}

Sindbis virus was fully inactivated by $6000 \mu$ joules $/ \mathrm{cm}^{2}$ of UVC radiation to single particles in solution according to data from the plaque assays, which was confirmed by data from the inoculation assays (Table 1). A dosage of $4500 \mu$ joules $/ \mathrm{cm}^{2}$ was not sufficient for inactivation. UVC irradiation appeared to cause minor formation of higher mass protein bands that were observable with SDS-PAGE (Fig. 1A, lane 3). Dynamic light scattering data showed a highly monodispersed peak near the expected particle radius with a PDI value of $0.26 \pm 0.03$, which is consistent with the data recorded for the untreated control sample (Fig. 2A, 2B). This indicates that no significant levels of aggregation or disintegration of virus particles resulted from full inactivation by treatment with $6000 \mu$ joules $/ \mathrm{cm}^{2}$. This is supported by image data obtained by TEM, wherein no aggregation or physical damage is observed within the limits of resolution (Fig. 3B). Higher dosages of UVC $\left(9000-15000 \mu\right.$ joules $\left./ \mathrm{cm}^{2}\right)$ similarly did not appear to cause detectable damage to the sample, although DLS data showed a small increase in hydrodynamic radius that appeared to correlate with increasing UV dosages (data not shown).

Inactivation of Sindbis virus microcrystals as described was not achieved with $6000 \mu \mathrm{joules} / \mathrm{cm}^{2}$ of UVC radiation. Irradiation at $30,000 \mu$ joules $/ \mathrm{cm}^{2}$ was also not sufficient, but full inactivation was achieved at $40,000 \mu$ joules $/ \mathrm{cm}^{2}$. At this level no evidence of infection was observed in the infectivity assays. It was noted that even low levels of UVC irradiation $\left(6000 \mu\right.$ joules $\left./ \mathrm{cm}^{2}\right)$ appeared to make the microcrystals resistant to dissolving in PN buffer. The cause of this may be related to UV induced protein-protein crosslinking, which was observed by SDS-PAGE (Fig. 1B, lane 3). It is apparent that the increased dosage of UVC used for the crystals resulted in more protein crosslinking than the lower dosage used with the single particles. Inactivation of the Sindbis virus microcrystals by UVC did not cause any visible deterioration of the microcrystals that could be observed with a polarized light microscope (Fig. 4B).

\subsection{Inactivation by Glutaraldehyde Crosslinking}

The infectivity assays showed that full inactivation of Sindbis viruses as single particles was accomplished with $0.1 \% \mathrm{v} / \mathrm{v}$ glutaraldehyde treatment for $24 \mathrm{hrs}$ at $4{ }^{\circ} \mathrm{C}$ (Table 1 ). Although no plaques were observed by plaque titration for the sample treated at a concentration of $0.01 \%$ glutarladehyde, the cultivation of a flask inoculated with the $0.01 \%$ glutaraldehyde sample did become fully infected after the second passage. Comparison of the $0.01 \%$ and $0.1 \%$ samples on SDS-PAGE (Fig. $1 \mathrm{~A}$, lanes 4,5 ) shows that there is a variation in the crosslinking effect of these two samples. At $0.1 \%$, visualization of the constituent proteins is prevented indicating a full crosslinking of the virion, but at $0.01 \%$ the three major structural proteins can still be observed, as well as the appearance of higher molecular mass bands indicating partial crosslinking between protein chains. A full crosslinking of the viral proteins is apparently required for full inactivation of the sample, although the partial crosslinking is nearly sufficient. Dynamic light scattering shows a monodispersed peak near the expected particle radius with 
a PDI value of $0.15 \pm 0.03$ for the fully inactivated sample, which is comparable with data for the untreated sample (Fig. 2A, 2C). This indicates that there is no particle-particle crosslinking, nor aggregation, and that the particles are fully intact. This is supported by TEM data as well (Fig. 3C). At $0.1 \%$ glutaraldehyde the effects of crosslinking are slightly apparent in the TEM images, where some of the external features of the virus appear more defined as a result of the increased stabilization conferred by crosslinking.

Sindbis microcrystals could also be successfully inactivated in hanging drops by diffusion of $0.1 \%$ glutaraldehyde. No evidence of infectivity was observed from either of the infectivity assays with treatment at this level. SDS-PAGE indicates that as with particles in solution, treatment of crystals with $0.1 \%$ glutaraldehyde fully crosslinks the particles (Fig. 1B, lane 4). Glutaraldehyde treated microcrystals appeared resistant to dissolving in PN buffer, which may indicate that crosslinking also occurs between particles within the lattice. Visualization of the crystals under a polarized light microscope reveals no obvious damage to the crystals following treatment with glutaraldehyde (Fig. 4C). X-ray diffraction has been reported previously for Sindbis microcrystals treated as described here with the exception that $0.5 \%$ glutaraldehyde was used (Lawrence et al., 2015). As reported in previous work (Harrison et al., 1992), it does not appear that glutaraldehyde treatment disrupts the crystal lattice in a manner that hinders $X$-ray diffraction at the medium resolution range of diffraction to which Sindbis virus crystals are limited.

\section{Discussion}

Neither UV irradiation nor glutaraldehyde treatment have been widely reported in literature for other members of the Togaviridae or Flaviviridae families (Delrue et al., 2012). However, a broad inactivation survey was reported in which gamma irradiation, $\beta$-propiolactone, or a combination of both were used to fully inactivate nine different arboviruses, including Sindbis (Goodman et al., 2014). In said study, all viruses demonstrated acceptable levels of virus-specific antigen activity (VSAA) with one or more inactivation conditions, according to ELISA methods. For each virus, there was some variation in the dosage levels that were required for full inactivation. It is likely that UV irradiation and/or glutaraldehyde treatment would also be capable of full inactivation of other arboviruses, providing that the appropriate dosage is first determined. It is not known how UV irradiation and glutaraldehyde treatment would affect the immunogenicity of these viruses.

Alterations to the physical structure of a virus at the molecular level are inherent to the mechanism of inactivation with glutaraldehyde. Although this is not ideal for high-resolution structural studies, it is a method that is regularly utilized in protein crystallography for stabilizing fragile crystals that would not otherwise tolerate freezing or handling. In such cases mosaicity can be reduced and resolution is sometimes improved as well (Lusty, 1999). Although it might be assumed that such alterations of the protein structure would be avoided by using UV irradiation, we show that this may not be the case with Sindbis virus when the sample is fully inactivated. SDS-PAGE revealed the slight appearance of larger mass protein bands upon exposure to $6,000 \mu$ joules $/ \mathrm{cm}^{2}$ UVC, and more significant crosslinking with microcrystals at $40,000 \mu$ joules $/ \mathrm{cm}^{2}$. Protein-RNA crosslinking may also occur, but given the $3804 \mathrm{kDa}$ single stranded RNA genome of Sindbis virus (Kibbe, 2007; Strauss et al., 1984), it would only be visible on a gel if significant UV-induced RNA strand cleavage also occurs. Although genomic crosslinking is thought to be the primary means by which UV radiation can inactivate, it is not known to what extent UV-induced protein crosslinking may contribute as well. UV and glutaraldehyde treatments did not appear to disrupt the crystal lattice when administered after crystallization as described; however 
crystallization of Sindbis virus following either means of inactivation resulted in the formation of less defined crystals and higher levels of amorphous precipitate (data not shown). Although it might be assumed that the majority of protein crosslinking occurs in the more protein dense capsid or envelope regions of the virus (Harrison et al., 1971), this may indicate that at least some crosslinking also occurs in exterior region where crystal contacts and epitopes are presumably located.

Full inactivation of the virus microcrystals with UVC radiation required a significantly higher dosage than what was used for the single particles in solution. In contrast, glutaraldehyde at $0.1 \%$ was sufficient to fully inactivate free viruses in solution as well as the microcrystals. It has also been observed with other work in the lab that when inactivating higher concentrations of Sindbis virus particles $\left(\sim 10^{11} \mathrm{pfu} / \mathrm{mL}\right)$, the dosage must be proportionally increased in order to fully inactivate via UVC irradiation, while the effects of treatment with glutaraldehyde at $0.01 \%$ or higher concentrations are more consistent regardless of particle concentration (data not shown). It thus appears possible that there is a difference in inactivation efficiency between the two methods. Full inactivation by UV light exposure is primarily dependent on the interaction of photons with nucleotides at certain positions within the genome of a randomly oriented virus. As the number of virus particles in a given sample volume increases, the probability of that interaction properly occurring with every single virus particle must also decrease. Given a stoichiometric excess of glutaraldehyde, each virus particle in solution is perhaps more likely to be fully and equally exposed within its chemical environment over a 24-hr period. This may account for the higher UV dosage required for the crystals, which were prepared from a virus concentration of 0.5 $\mathrm{mg} / \mathrm{mL}$ compared to the $0.07 \mathrm{mg} / \mathrm{mL}$ used for the particles in solution. Because virus particles on the surface of a crystal will absorb UV, it is also possible that UV exposure is significantly more intense on the crystal surface, than its interior. Although the UV-exposed crystals were resistant to dissolving, the extent to which they do stay intact during the infectivity assays is not known. It is likely that the process of pipetting and sample handling alone is sufficient to chip or fracture some crystals and thereby expose particles previously stationed toward the interior of the lattice. Glutaraldehyde $\left(\mathrm{C}_{5} \mathrm{H}_{8} \mathrm{O}_{2}\right)$ as a small molecule is capable of diffusion through the crystal via solvent channels within the crystal lattice (Yan et al., 2015), and may be more likely to fully penetrate the lattice during the 6-day vapor diffusion period used here for inactivation.

Glutaraldhyde crosslinking has been used successfully in the development of a vaccine against the bacteria Bordetella pertussis that causes whooping cough (Gupta et al., 1987). It has also been reported in the literature for use with an experimental virus vaccine against bovine respiratory syncytial virus (BRSV), for which it was successful in producing virus-specific neutralizing antibodies (Keles et al., 1998). Glutaraldehyde use as a fixing agent began in the early 1960s (Sabatini et al., 1963), after formaldehyde treatment was established in vaccine development (Salk et al., 1954). Formaldehyde inactivation continues to be used more extensively in vaccines today. Poliovirus (PV), hepatitis A virus (HAV), Japanese encephalitis virus (JEV), tick borne encephalitis virus (TBEV), rabies virus, and influenza virus each have licensed inactivated vaccines produced from formaldehyde inactivated particles (Sanders et al., 2015). Vaccines for viruses inactivated with UV irradiation have been proven to be effective in producing virus-specific immune responses for murine leukemia virus strain Cas-Br-M (UV-Cas) (Sarzotti et al., 1994) and porcine reproductive and respiratory syndrome virus (PRRSV) (Vanhee et al., 2009), but this was not the case with the UV-inactivated vaccine for rabbit hemorrhagic disease virus (RHDV) (Henning et al., 2005).

Although the inactivation of microcrystals is generally more applicable to structural studies that employ diffraction, it should be noted that it may be relevant to vaccine development as well. Glutaraldehyde crosslinked protein crystals (CLPCs) of human serum albumin $\sim 2 \mu \mathrm{m}$ in size were investigated as a 
subunit vaccine, and demonstrated a significantly higher (up to 30-fold increase) immunogenic response than the soluble antigen (St Clair et al., 1999). The self-adjuvant effect of crystallization on the antigen was attributed to a combination of the depot effect (slowed release), the increased particulate size, and repeating structure of the microcrystals. It may be worth considering how this approach might be similarly applied to inactivated virus vaccines as a means to produce an improved immune response.

Conversely, crosslinking or inactivation of virus particles in solution is not entirely limited to use with vaccine development, but may also be relevant to emerging single particle methods for investigating structure. Cryo-electron microscopy (Cryo-EM) techniques have produced increasingly higher resolution single particle image reconstructions of biological samples, and are expected to continue on their trajectory toward atomic resolution (Glaeser, 2016). Among the methods being used to increase resolution with cryo-EM is partial fixing of samples by centrifugation through an aldehyde containing gradient, which stabilizes the sample and reduces heterogeneity (Kastner et al., 2008; Stark, 2010). Sample stability and homogeneity are likewise important for serial femtosecond X-ray (SFX) sample delivery methods that are used for emerging single particle structural investigations at X-ray FreeElectron Laser (XFEL) sources (Aquila et al., 2015; Ekeberg et al., 2015; Hosseinizadeh et al., 2015). Glutaraldehyde crosslinking might be of similar benefit to the SFX single particle studies, in addition to also being functional in inactivating the sample. Unless current or future XFEL sources are equipped to accommodate infectious pathogens according to biosafety standards, any investigation of potentially hazardous virus samples will either be disallowed or require a thorough demonstration of inactivation of the sample with glutaraldehyde, UV, or another means.

\section{Conclusions}

A number of viruses have been fully inactivated by various means, including UV irradiation, formaldehyde and glutaraldehyde treatment (Delrue et al., 2012). Here, we demonstrate how UV and glutaraldehyde methods can be utilized to fully inactivate purified Sindbis alphavirus particles in solution at a density of approximately $10^{10} \mathrm{pfu} / \mathrm{mL}$, and we also show that the method can be extended to Sindbis viruses in microcrystalline form. Both methods of inactivation produced no apparent denaturation or aggregation of particles in solution, and may be compatible with biophysical studies at facilities that are not equipped for handling samples that are of pathogenic risk. Immunogenic studies can be applied to determine if these approaches have relevance for vaccine development. These methods would likely extend to other related viruses in Togaviridae or Flaviviridae, providing that the appropriate dosage is determined for a given virus. Given the human risk of viruses in these families, and the variety of applications that might require the use of a fully inactivated and fully intact virus sample, the methods described herein for the purified Sindbis virus both in solution at high particle density and in crystalline form may be of use for various medically-relevant research purposes.

Acknowledgements:

This work was supported by U.S. National Science Foundation (NSF) Award No. 1120997, NSF STC BioXFEL Center Award No. 1231306, and National Institutes of Health U54 GM094599.

Table and Figure Captions:

Table 1. Infectivity assay results for inactivation of Sindbis virus with UVC irradiation (above) and glutaraldehyde treatment (below). 
Figure 1. SDS-PAGE analysis of active (untreated) and inactivated virus particles in solution (A.) and in crystals (B.). Crosslinking of the structural proteins (E1, E2, C) is indicated by the appearance of larger molecular mass bands and the disappearance of the expected bands.

Figure 2. Dynamic Light Scattering data for virus particles in solution. Hydrodynamic radius plots (left) were determined from CONTIN analysis, and correlation plots with polydispersity index values (right) were determined from cumulants analysis. The hydrodynamic radius and polydispersity index values for the samples inactivated by UV irradiation (B.) or glutaraldehyde treatment (C.) did not change significantly compared to the untreated sample (A.), which indicates that UV and glutaraldehyde inactivation did not cause significant aggregation or degradation in the sample.

Figure 3. Transmission Electron Microscope images of Sindbis virus particles inactivated by UVC irradiation (B.) or glutaraldehyde treatment (C.) appear visibly unchanged in comparison to particles that are active (A.). Images were taken at 53,000X magnification.

Figure 4. Polarized light microscope images of Sindbis virus microcrystals. Compared with untreated crystals (A.), inactivation by UVC irradiation (B.) or glutaraldehyde treatment (C.) did not appear to cause any significant damage to the physical state of the crystals.

References:

Adams, M.J., Lefkowitz, E.J., King, A.M.Q., Bamford, D.H., Breitbart, M., Davison, A.J., Ghabrial, S.A., Gorbalenya, A.E., Knowles, N.J., Krell, P., Lavigne, R., Prangishvili, D., Sanfaçon, H., Siddell, S.G., Simmonds, P., Carstens, E.B., 2015. Ratification vote on taxonomic proposals to the International Committee on Taxonomy of Viruses (2015). Arch. Virol. 160, 1837-1850. doi:10.1007/s00705-0152425-z

Adams, M.J., Lefkowitz, E.J., King, A.M.Q., Bamford, D.H., Breitbart, M., Davison, A.J., Ghabrial, S.A., Gorbalenya, A.E., Knowles, N.J., Krell, P., Lavigne, R., Prangishvili, D., Sanfaçon, H., Siddell, S.G., Simmonds, P., Carstens, E.B., 2014. Ratification vote on taxonomic proposals to the International Committee on Taxonomy of Viruses (2015). Arch. Virol. 159, 2831-2841. doi:10.1007/s00705-0152425-z

Adouchief, S., Smura, T., Sane, J., Vapalahti, O., Kurkela, S., 2016. Sindbis virus as a human pathogenepidemiology, clinical picture and pathogenesis. Rev. Med. Virol. doi: 10.1002/rmv.1876.

Aquila, A., Barty, A., Bostedt, C., Boutet, S., Carini, G., DePonte, D., Drell, P., Doniach, S., Downing, K.H., Earnest, T., Elmlund, H., Elser, V., G??hr, M., Hajdu, J., Hastings, J., Hau-Riege, S.P., Huang, Z., Lattman, E.E., Maia, F.R.N.C., Marchesini, S., Ourmazd, A., Pellegrini, C., Santra, R., Schlichting, I., Schroer, C., Spence, J.C.H., Vartanyants, I.A., Wakatsuki, S., Weis, W.I., Williams, G.J., 2015. The linac coherent light source single particle imaging road map. Struct. Dyn. 2. doi:10.1063/1.4918726

Avrameas, S., Ternynck, T., 1969. The cross-linking of proteins with glutaraldehyde and its use for the preaparation of immunoadsorbernts. Immunochemistry 6, 53-66. doi:10.1016/00192791(69)90178-5

Bowes, J.H., Cater, C.W., 1968. The interaction of aldehydes with collagen. Biochim. Biophys. Acta 168, 341-352. doi:10.1016/0005-2795(68)90156-6

Delrue, I., Verzele, D., Madder, A., Nauwynck, H.J., 2012. Inactivated virus vaccines from chemistry to prophylaxis: merits, risks and challenges. Expert Rev Vaccines 11, 695-719. doi:10.1586/erv.12.38

Eischeid, A.C., Linden, K.G., 2011. Molecular indications of protein damage in adenoviruses after UV 
disinfection. Appl. Environ. Microbiol. 77, 1145-1147. doi:10.1128/AEM.00403-10

Ekeberg, T., Svenda, M., Abergel, C., Maia, F.R.N.C., Seltzer, V., Claverie, J., Hantke, M., Jönsson, O., Nettelblad, C., Schot, G. Van Der, Liang, M., Deponte, D.P., Barty, A., Seibert, M.M., Iwan, B., Andersson, I., Loh, N.D., Martin, A. V, Chapman, H., Bostedt, C., Bozek, J.D., Ferguson, K.R., Krzywinski, J., Epp, S.W., Rolles, D., 2015. Three-Dimensional Reconstruction of the Giant Mimivirus Particle with an X-Ray Free-Electron Laser. Phys. Rev. Lett. 114, 098102. doi:10.1103/PhysRevLett.114.098102

Fraenkel-Conrat, H., Mecham, D.K., 1949. The reaction of formaldehyde with proteins: VII. Demonstration of intermolecular cross-linking by means of osmotic pressure measurements. J. Biol. Chem. 177, 477-486.

Fraenkel-Conrat, H., Olcott, H.S., 1948. Reaction of formaldehyde with proteins: VI. Cross-linking of animo groups with phenol, imidazole, or indole groups. J. Biol. Chem. 174, 827-843.

French, D., Edsall, J.T., 1945. The Reactions of Formaldehyde with Amino Acids and Proteins. Adv. Protein Chem. 2, 277-335. doi:10.1016/S0065-3233(08)60627-0

Frisken, B.J., 2001. Revisiting the Method of Cumulants for the Analysis of Dynamic Light-Scattering Data. Appl. Opt. 40, 4087. doi:10.1364/AO.40.004087

Glaeser, R.M., 2016. How good can cryo-EM become ? Nat Methods 13, 28-32. doi:10.1038/nmeth.3695 Goodman, C.H., Russell, B.J., Velez, J.O., Laven, J.J., Nicholson, W.L., Bagarozzi, D.A., Moon, J.L., Bedi, K., Johnson, B.W., 2014. Development of an algorithm for production of inactivated arbovirus antigens in cell culture. J. Virol. Methods 208, 66-78. doi:10.1016/j.jviromet.2014.07.030

Gupta, R.K., Sharma, S.B., Ahuja, S., Saxena, S.N., 1987. Glutaraldehyde inactivated pertussis vaccine: a less histamine sensitizing vaccine. J. Biol. Stand. 15, 159-164. doi:10.1016/0092-1157(87)90038-2

Habeeb, A.F.S.A., Hiramoto, R., 1968. Reaction of proteins with glutaraldehyde. Arch. Biochem. Biophys. 126, 16-26. doi:10.1016/0003-9861(68)90554-7

Harrison, S.C., David, A., Jumblatt, J., Darnell, J.E., 1971. Lipid and protein organization in sindbis virus. J. Mol. Biol. 60, 523-528.

Harrison, S.C., Strong, R.I.L., Schlesinger, S., Schlesinger, M.J., Euclid, S., Louis, S., 1992. Crystallization of Sindbis Virus and its Nucleocapsid. J. Mol. Biol. 226, 277-280.

He, L., Piper, a., Meilleur, F., Hernandez, R., Heller, W.T., Brown, D.T., 2012. Conformational Changes in Sindbis Virus Induced by Decreased pH Are Revealed by Small-Angle Neutron Scattering. J. Virol. 86, 1982-1987. doi:10.1128/JVI.06569-11

Henning, J., Meers, J., Davies, P.R., 2005. Exposure of rabbits to ultraviolet light-inactivated rabbit haemorrhagic disease virus (RHDV) and subsequent challenge with virulent virus. Epidemiol. Infect. 133, 731-735. doi:10.1017/S0950268805003754

Hernandez, R., Brown, D., 2005. Sindbis Virus : Propagation, Quantification , and Storage. Curr. Protoc. Microbiol. 15B, 1-34.

Hopwood, D., 1975. The reactions of glutaraldehyde with nucleic acids. Histochem. J. 7, 267-276.

Hosseinizadeh, A., Dashti, A., Schwander, P., Fung, R., Ourmazd, A., 2015. Single-particle structure determination by X-ray free-electron lasers: Possibilities and challenges. Struct. Dyn. 2, 1-8. doi:10.1063/1.4919740

Huang, H., Hopkins, P.B., 1993. DNA Interstrand Cross-Linking by Formaldehyde - Nucleotide-Sequence Preference and Covalent Structure of the Predominant Cross-Link Formed in Synthetic Oligonucleotides. J. Am. Chem. Soc. 115, 9402-9408. doi:10.1021/ja00074a005

International Standard ISO13321 Methods for Determination of Particle Size Distribution Part 8: Photon Correlation Spectroscopy, 1996. , in: International Organization for Standardization (ISO).

International Standard ISO22412 Particle Size Analysis - Dynamic Light Scattering, 2008. , in: International Organization for Standardization (ISO).

Kastner, B., Fischer, N., Golas, M.M., Sander, B., Dube, P., Boehringer, D., Hartmuth, K., Deckert, J., 
Hauer, F., Wolf, E., Uchtenhagen, H., Urlaub, H., Herzog, F., Peters, J.M., Poerschke, D., Lührmann, R., Stark, H., 2008. GraFix: sample preparation for single-particle electron cryomicroscopy. Nat. Methods 5, 53-55. doi:10.1038/nmeth1139

Keles, I., Woldehiwet, Z., Murray, R.D., 1998. Vaccination with glutaraldehyde-fixed bovine respiratory syncytial virus (BRSV)-infected cells stimulates a better immune response in lambs than vaccination with heat-inactivated cell-free BRSV. Vaccine 16, 1172-1178. doi:10.1016/S0264-410X(98)80116-3

Kibbe, W.A., 2007. OligoCalc: An online oligonucleotide properties calculator. Nucleic Acids Res. 35, 4346. doi:10.1093/nar/gkm234

Lawrence, R.M., Conrad, C.E., Zatsepin, N. a., Grant, T.D., Liu, H., James, D., Nelson, G., Subramanian, G., Aquila, A., Hunter, M.S., Liang, M., Boutet, S., Coe, J., Spence, J.C.H., Weierstall, U., Liu, W., Fromme, P., Cherezov, V., Hogue, B.G., 2015. Serial femtosecond X-ray diffraction of enveloped virus microcrystals. Struct. Dyn. 2, 041720. doi:10.1063/1.4929410

Lu, K., Ye, W., Zhou, L., Collins, L.B., Chen, X., Gold, A., Louise, M., Swenberg, J.A., Hill, C., 2010. Structural characterization of formaldehyde-induced cross-links between amino acids and deoxynucleosides and their oligomers. J. Am.Chem. Soc. 132, 3388-3399. doi:10.1021/ja908282f.Structural

Lusty, C.J., 1999. A gentle vapor-diffusion technique for cross-linking of protein crystals for cryocrystallography. J. Appl. Crystallogr. 32, 106-112. doi:10.1107/S002188989801053X

Markwell, M. a, Haas, S.M., Bieber, L.L., Tolbert, N.E., 1978. A modification of the Lowry procedure to simplify protein determination in membrane and lipoprotein samples. Anal. Biochem. 87, 206-210. doi:10.1016/0003-2697(78)90586-9

Mcdonnell, G., Russell, a. D., 1999. Antiseptics and disinfectants: Activity, action, and resistance. Clin. Microbiol. Rev. 12, 147-179. doi:0893-8512/99/\$04.001

Migneault, I., Dartiguenave, C., Bertrand, M.J., Waldron, K.C., 2004. Glutaraldehyde: Behavior in aqueous solution, reaction with proteins, and application to enzyme crosslinking. Biotechniques 37, 790-802.

Nimni, M.E., Cheung, D., Strates, B., Kodama, M., Sheikh, K., 1987. Chemically modified collagen: a natural biomaterial for tissue replacement. J. Biomed. Mater. Res. 21, 741-771.

Okuda, K., Urabe, I., Yamada, Y., Okada, H., 1991. Reaction of glutaraldehyde with amino and thiol compounds. J. Ferment. Bioeng. 71, 100-105. doi:10.1016/0922-338X(91)90231-5

Paredes, A., Weaver, S., Watowich, S., Chiu, W., 2005. Structural biology of old world and new world alphaviruses. Arch. Virol. 1-7.

Paredes, A.M., Brown, D.T., Rothnagel, R., Chiu, W., Schoepp, R.J., Johnston, R.E., Prasad, B. V, 1993. Three-dimensional structure of a membrane-containing virus. Proc. Natl. Acad. Sci. U. S. A. 90, 9095-9099. doi:10.1073/pnas.90.19.9095

Prinsze, C., Dubbelman, T.M.A.R., Van Steveninck, J., 1990. Protein damage, induced by small amounts of photodynamically generated singlet oxygen or hydroxyl radicals. Biochim. Biophys. Acta (BBA)/Protein Struct. Mol. 1038, 152-157. doi:10.1016/0167-4838(90)90198-O

Provencher, S.W., 1982. A constrained regularization method for inverting data represented by linear algebraic or integral equations. Comput. Phys. Commun. 27, 213-227. doi:10.1016/00104655(82)90173-4

Ravanat, J.-L., Douki, T., Cadet, J., 2001. Direct and indirect effects of UV radiation on DNA and its components. J. Photochem. Photobiol. B Biol. 63, 88-102. doi:10.1016/S1011-1344(01)00206-8

SABATINI, D.D., BENSCH, K., BARRNETT, R.J., 1963. Cytochemistry and electron microscopy. The preservation of cellular ultrastructure and enzymatic activity by aldehyde fixation. J. Cell Biol. 17, 19-58. doi:10.1083/jcb.17.1.19

Saito, I., Matsuura, T., 1985. Chemical Aspects of UV-Induced Cross-Linking of Proteins to Nucleic Acids. Photoreactions with Lysine and Tryptophan. Acc. Chem. Res. 18, 134-141. 
Salk, J.E., Krech, U., Younger, J.S., Bennet, B.L., Lewis, L.J., Bazeley, P.L., 1954. Formaldehyde treatment and safety testing of experimental poliomyelitis vaccines. Am. J. Public Health 44, 563-570.

Sanders, B., Koldijk, M., Schuitemaker, H., 2015. Vaccine analysis: Strategies, principles, and control, in: Vaccine Analysis: Strategies, Principles, and Control. pp. 45-80. doi:10.1007/978-3-662-45024-6

Sarzotti, M., Dean, T., Remington, M., Hoffman, P., 1994. Ultraviolet-light-inactivated Cas-Br-M murine leukemia virus induces a protective $\mathrm{CD} 8+$ cytotoxic $\mathrm{T}$ lymphocyte response in newborn mice. AIDS Res. Hum. Retroviruses 10, 1695-1702.

Schägger, H., 2006. Tricine-SDS-PAGE. Nat. Protoc. 1, 16-22. doi:10.1038/nprot.2006.4

Schott, H.N., Shetlar, M.D., 1974. Photochemical addition of amino acids to thymine. Biochem. Biophys. Res. Commun. 59, 1112-1116. doi:10.1017/CBO9781107415324.004

Sewell, B.T., Bouloukos, C., von Holt, C., 1984. Formaldehyde and glutaraldehyde in the fixation of chromatin for electron microscopy. J. Microsc.

Shetlar, M.D., Schott, H.N., Martinson, H.G., Lin, E.T., 1975. Formation of thymine-lysine adducts in irradiated DNA lysine systems. Biochem. Biophys. Res. Commun. 66, 88-93. doi:10.1016/j.bbrc.2008.06.040

St Clair, N., Shenoy, B., Jacob, L.D., Margolin, A.L., 1999. Cross-linked protein crystals for vaccine delivery. Proc. Natl. Acad. Sci. U. S. A. 96, 9469-74. doi:10.1073/pnas.96.17.9469

Stark, H., 2010. GraFix: Stabilization of fragile macromolecular complexes for single particle Cryo-EM, Methods in Enzymology. Elsevier Masson SAS. doi:10.1016/S0076-6879(10)81005-5

Strauss, E.G., Rice, C.M., Strauss, J.H., 1984. Complete nucleotide sequence of the genomic RNA of Sindbis virus. Virology 133, 92-110.

Strauss, J.H., Strauss, E.G., 2001. Virus evolution: How does an enveloped virus make a regular structure? Cell 105, 5-8. doi:10.1016/S0092-8674(01)00291-4

Vanhee, M., Delputte, P.L., Delrue, I., Geldhof, M.F., Nauwynck, H.J., 2009. Development of an experimental inactivated PRRSV vaccine that induces virus-neutralizing antibodies. Vet. Res. 40, $<10.1051 /$ vetres/2009046>. <hal-00903116>. doi:10.1051/vetres/2009046

Wigginton, K.R., Menin, L., Montoya, J.P., Kohn, T., 2010. Oxidation of virus proteins during UV 254 and singlet oxygen mediated inactivation. Environ. Sci. Technol. 44, S1-S17.

Wigginton, K.R., Menin, L., Sigstam, T., Gannon, G., Cascella, M., Hamidane, H. Ben, Tsybin, Y.O., Waridel, P., Kohn, T., 2012. UV radiation induces genome-mediated, site-specific cleavage in viral proteins. Chembiochem 13, 837-45. doi:10.1002/cbic.201100601

Yan, E.-K., Cao, H.-L., Zhang, C.-Y., Lu, Q.-Q., Ye, Y.-J., He, J., Huang, L.-J., Yin, D.-C., 2015. Cross-linked protein crystals by glutaraldehyde and their applications. RSC Adv. 5, 26163-26174. doi:10.1039/C5RA01722J

Yoon, J.H., Lee, C.S., O'Connor, T.R., Yasui, a, Pfeifer, G.P., 2000. The DNA damage spectrum produced by simulated sunlight. J. Mol. Biol. 299, 681-693. doi:10.1006/jmbi.2000.3771 


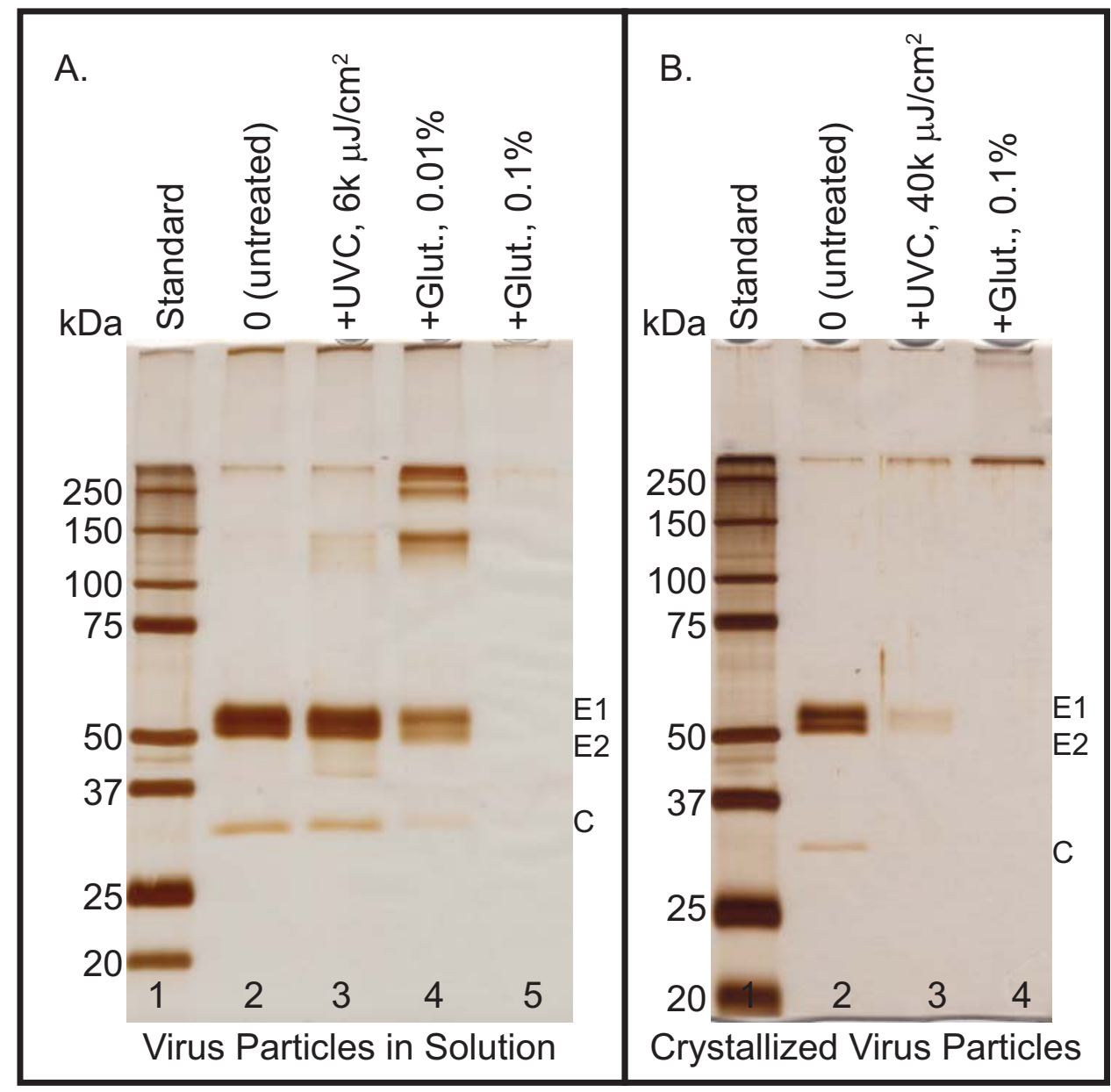


A. Untreated (active)
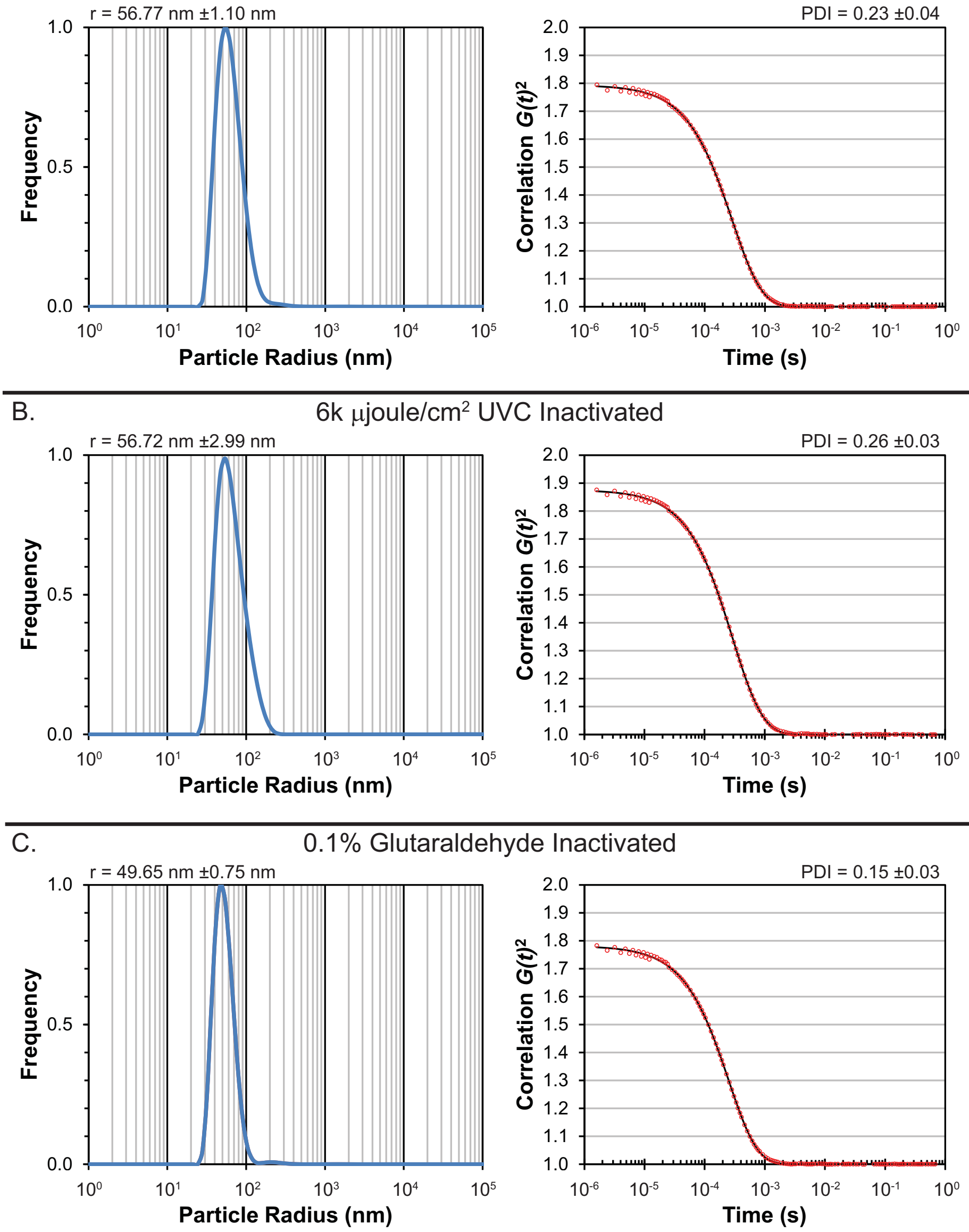


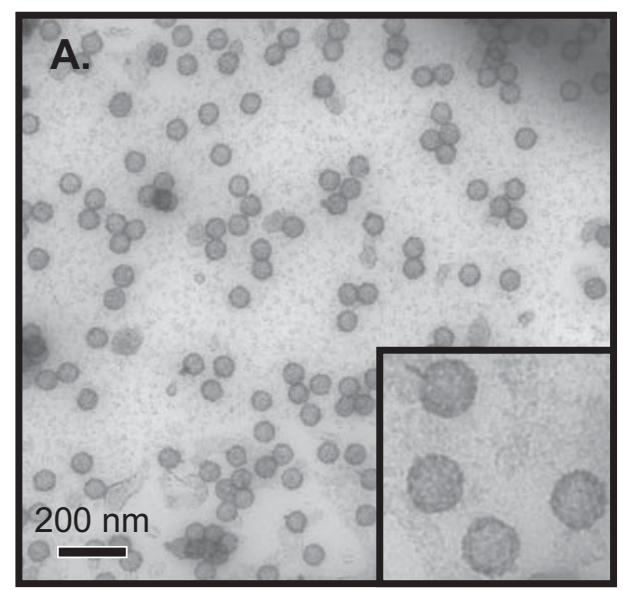

Untreated (active)

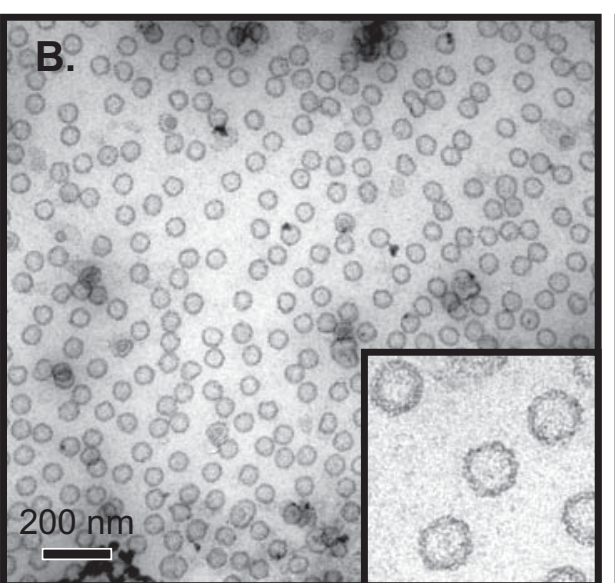

UVC Inactivated

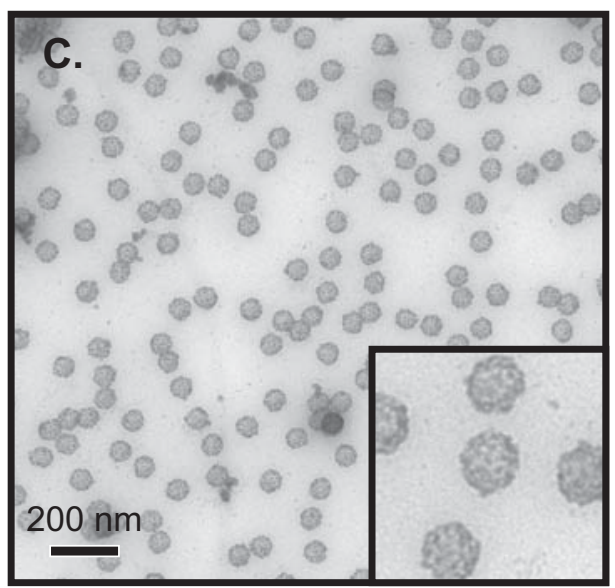

Glutaraldehyde Inactivated 


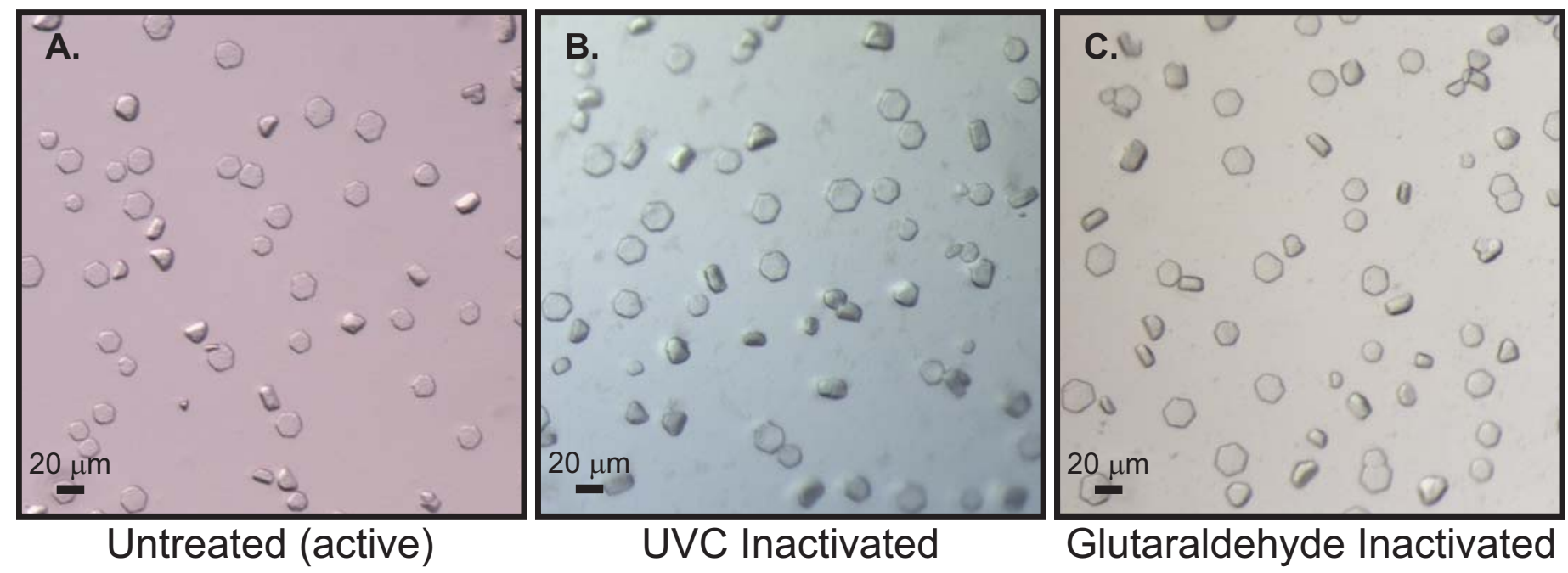


Table 1.

\begin{tabular}{|l|l|c|}
\hline $\begin{array}{c}\text { UVC Dosage } \\
\left(\mu \text { joules } / \mathrm{cm}^{2}\right)\end{array}$ & $\begin{array}{c}\text { Plaque Assay } \\
\text { Titer }(\mathrm{pfu} / \mathrm{mL})\end{array}$ & $\begin{array}{c}\text { Inoculation Assay } \\
\text { Infectivity }(+/-)\end{array}$ \\
\hline 0 (untreated) & $1.8 \times 10^{10}$ & + \\
\hline 1500 & $4.0 \times 10^{4}$ & + \\
\hline 3000 & $1.3 \times 10^{2}$ & + \\
\hline 4500 & $1.3 \times 10^{1}$ & + \\
\hline 6000 & $<2.5$ & - \\
\hline 9000 & $<2.5$ & - \\
\hline 12000 & $<2.5$ & - \\
\hline 15000 & $<2.5$ & - \\
\hline
\end{tabular}

\begin{tabular}{|l|l|c|}
\hline $\begin{array}{c}\text { Glutaraldehyde } \\
\text { Dosage (\% v/v) }\end{array}$ & \multicolumn{1}{|c|}{$\begin{array}{c}\text { Plaque Assay } \\
\text { Titer (pfu/mL) }\end{array}$} & $\begin{array}{c}\text { Inoculation Assay } \\
\text { Infectivity (+/-) }\end{array}$ \\
\hline 0 (untreated) & $5.5 \times 10^{9}$ & + \\
\hline $0.0001 \%$ & $1.5 \times 10^{9}$ & + \\
\hline $0.001 \%$ & $1.5 \times 10^{7}$ & + \\
\hline $0.01 \%$ & $<2.5$ & + \\
\hline $0.1 \%$ & $<2.5$ & - \\
\hline
\end{tabular}




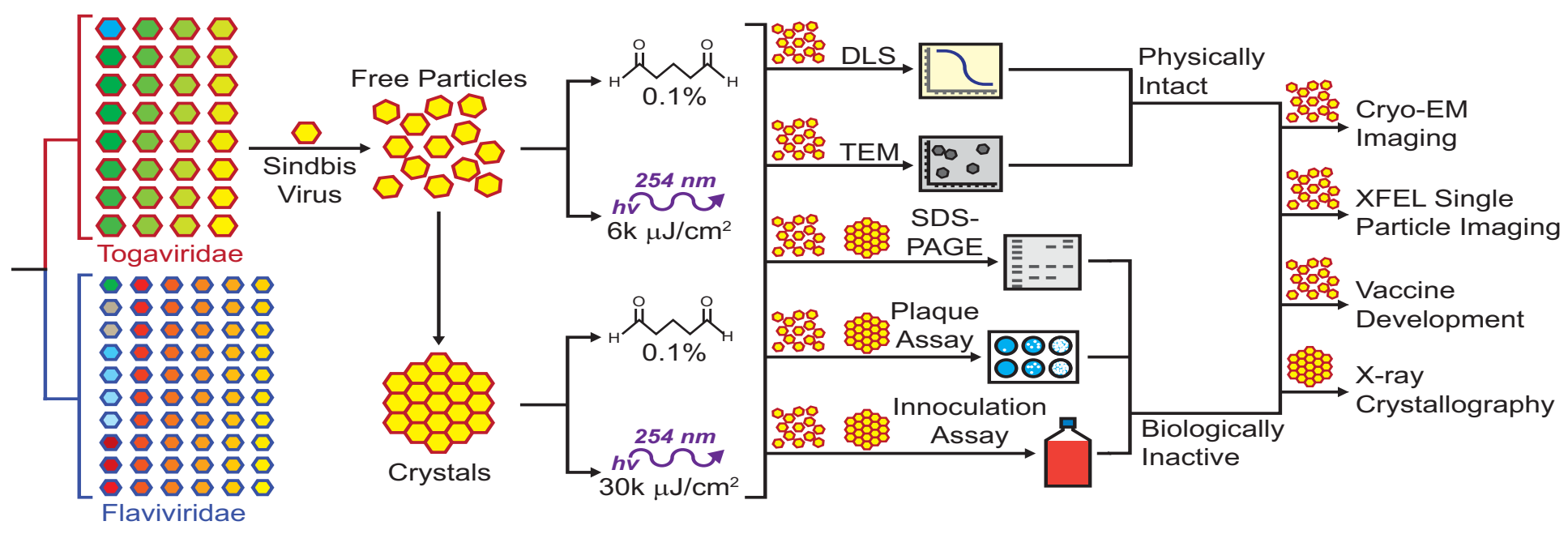

